\title{
Classification of Centers for Disease Control Group Eugonic Fermenter (EF)-4a and EF-4b as Neisseria animaloris sp. nov. and Neisseria zoodegmatis sp. nov., respectively
}

\author{
Peter Vandamme, ${ }^{1}$ Barry Holmes, ${ }^{2}$ Hervé Bercovier ${ }^{3}$ and Tom Coenye ${ }^{1}$ \\ ${ }^{1}$ Laboratorium voor Microbiologie, Universiteit Gent, Gent, Belgium \\ ${ }^{2}$ National Collection of Type Cultures, HPA Centre for Infections, Colindale, London, UK \\ ${ }^{3}$ Hebrew University Medical School, Ein Karem, Jerusalem, Israel
}

\begin{abstract}
A polyphasic taxonomic study was performed on isolates classified as Centers for Disease Control Group Eugonic Fermenter (EF)-4a and EF-4b. Comparative 16S rRNA gene sequence analysis confirmed that group EF-4a and EF-4b belong to the genus Neisseria with Neisseria canis and Neisseria dentiae as the nearest phylogenetic neighbours. DNA-DNA hybridizations and biochemical analyses demonstrated that isolates of group EF-4a and EF-4b represent two novel species within this sublineage of the genus Neisseria. Based on the results of the present study, isolates of group EF-4a and EF-4b are classified as Neisseria animaloris sp. nov. (type strain LMG $23011^{\top}=$ NCTC $12228^{\top}$ ) and Neisseria zoodegmatis sp. nov. (type strain LMG $23012^{\top}=$ NCTC $12230^{\top}$ ), respectively.
\end{abstract}

The designation Centers for Disease Control Group Eugonic Fermenter 4 (EF-4) was first used by Tatum et al. (1974) for a group of Gram-negative saccharolytic organisms predominantly recovered from human wounds resulting from dog or cat bites. EF-4 isolates are considered to be commensal organisms found in the oral cavity of dogs and cats, although systemic infections in humans and animals have also been reported (Ganière et al., 1995). Two biotypes can be distinguished based on the presence (EF-4a) or absence (EF-4b) of arginine dihydrolase activity (Holmes \& Ahmed, 1981). In addition, both biotypes can be distinguished based on DNA G + C content (Bercovier et al., 1982), cellular fatty acid content (Dees et al., 1981) and whole-cell protein analysis (Holmes et al., 1990). Analysis of rRNA gene sequence similarities indicated that EF-4 strains were closely related to the genus Neisseria (Rossau et al., 1989) and this was later confirmed by a detailed numerical phenotypic taxonomic study (Barrett \& Sneath, 1994). In the present study, a polyphasic taxonomic study was performed to classify both taxa formally.

EF-4 strains used in this study are listed in Table 1 and were well-chosen representatives of previous taxonomic studies

The GenBank/EMBL/DDBJ accession numbers for the $16 \mathrm{~S}$ rRNA gene sequences of strains LMG $23011^{\top}$ and LMG $23012^{\top}$ are D0006842 and D0006843, respectively.

The fatty acid contents of Neisseria animaloris sp. nov., Neisseria zoodegmatis sp. nov. and related taxa are presented in a supplementary table in IJSEM online.
(Holmes et al., 1990; Rossau et al., 1989). All strains were grown aerobically on trypticase soy agar $(\mathrm{BBL})$ at $37^{\circ} \mathrm{C}$ unless otherwise indicated.

DNA for 16S rRNA gene sequencing was prepared by heating one or two colonies at $95^{\circ} \mathrm{C}$ for $15 \mathrm{~min}$ in $20 \mu \mathrm{l}$ lysis buffer containing $0.25 \%(\mathrm{w} / \mathrm{v})$ SDS and $0.05 \mathrm{M} \mathrm{NaOH}$. Following lysis, $180 \mu \mathrm{l}$ distilled water was added to the lysate. 16S rRNA genes were amplified using oligonucleotide primers complementary to highly conserved regions of bacterial $16 \mathrm{~S}$ rRNA genes. The forward primer was $5^{\prime}$-AGAGTTTGATCCTGGCTCAG-3' (hybridizing at positions 8-27, according to the Escherichia coli numbering system) and the reverse primer was 5'-AAGGAGGTGATCCAGCCGCA-3' (hybridizing at positions 1541-1522). PCR products were purified using a NucleoFast 96 PCR clean-up kit (Macherey-Nagel). Sequencing reactions were performed by using a BigDye terminator cycle sequencing kit (Applied Biosystems) and purified with a Montage $\mathrm{SEQ}_{96}$ sequencing reaction clean-up kit (Millipore). Sequencing was performed with an ABI Prism 3100 Genetic Analyzer (Applied Biosystems). The eight sequencing primers used are listed in Coenye et al. (1999). Sequence assembly was performed using the AUTOASSEMBLER program (Applied Biosystems). Sequences were aligned with sequences retrieved from GenBank using CLUSTAL_X (Thompson et al., 1997). Phylogenetic analyses and bootstrap analysis (1000 replicates) were subsequently performed using the BioNumerics 4.01 software package (Applied Maths). A phylogenetic tree was constructed using the neighbour-joining method (Saitou \& 
Table 1. List of strains studied

Strain designations beginning with CL are designations used by the National Collection of Type Cultures Identification Services Laboratory.

\begin{tabular}{|c|c|}
\hline Strain designation & Source \\
\hline \multicolumn{2}{|l|}{ Neisseria animaloris sp. nov. (EF-4a) } \\
\hline LMG $23011^{\mathrm{T}}\left(=\right.$ NCTC $12228^{\mathrm{T}}=$ CL $191 / 78^{\mathrm{T}}=$ ATCC $29858^{\mathrm{T}}=$ CDC D8251 $\left.{ }^{\mathrm{T}}\right)$ & Thumb wound, Wisconsin, USA \\
\hline LMG $23009(=$ NCTC $12226=$ CL $480 / 77)$ & Dog-bite wound, London, UK \\
\hline LMG $23010(=$ NCTC $12227=$ CL $643 / 80=$ CIP 268.80$)$ & Abscess following dog-bite, Montreuil, France \\
\hline \multicolumn{2}{|l|}{ Neisseria zoodegmatis sp. nov. (EF-4b) } \\
\hline LMG $23012^{\mathrm{T}}\left(=\right.$ NCTC $12230^{\mathrm{T}}=$ CL $194 / 78^{\mathrm{T}}=$ ATCC $29859^{\mathrm{T}}=$ CDC D5986 $\left.{ }^{\mathrm{T}}\right)$ & Dog-bite wound, Hawaii, USA \\
\hline LMG $23013(=$ NCTC $12229=$ CL $641 / 80=$ CIP 784.80$)$ & Dog-bite wound, Paris, France \\
\hline LMG $23014(=$ NCTC $12231=$ CL $724 / 80=$ CDC C669 $)$ & Vagina, Canada \\
\hline
\end{tabular}

Nei, 1987); bases that could not unequivocally identified were discarded for analyses. Almost complete 16S rRNA gene sequences were determined for two EF-4 strains, LMG $23011^{\mathrm{T}}$ and LMG $23012^{\mathrm{T}}$. Partial sequences of about 450 bases were generated for strains LMG 23009, LMG 23010, LMG 23013 and LMG 23014. The 16S rRNA gene sequence of LMG $23011^{\mathrm{T}}$ shared the highest similarity values with Neisseria canis LMG $8383^{\mathrm{T}}(97.9 \%)$, group EF-4b strain LMG $23012^{\mathrm{T}}(97 \cdot 7 \%)$ and Neisseria dentiae LMG $23015^{\mathrm{T}}$ $(97 \cdot 1 \%)$. The $16 \mathrm{~S}$ rRNA gene sequence of LMG $23012^{\mathrm{T}}$ was most similar to those of $N$. canis LMG $8383^{\mathrm{T}}(98 \cdot 1 \%)$ and $N$. dentiae LMG $23015^{\mathrm{T}}(97 \cdot 9 \%)$. 16S rRNA gene sequence similarities of strains LMG $23011^{\mathrm{T}}$ and LMG $23012^{\mathrm{T}}$ with Uruburuella suis CCUG $47806^{\mathrm{T}}$ and other Neisseria species were below $97 \%$. The 447-base fragment of the $16 \mathrm{~S}$ rRNA gene sequence of strain LMG 23010 was $100 \%$ similar to the corresponding fragment of strain LMG $23011^{\mathrm{T}}$; the 447 base fragment of the 16S rRNA gene sequence of strain LMG 23009 differed by two bases from the corresponding fragment of the other two strains (data not shown). Finally, the 452-base fragments of the $16 \mathrm{~S}$ rRNA gene sequence of strains LMG 23013 and LMG 23014 were $100 \%$ similar to the corresponding fragment of strain LMG $23012^{\mathrm{T}}$ (data not shown).

In order to determine the degree of relatedness between representative group EF-4a and EF-4b strains, DNA-DNA hybridization experiments were performed between strains LMG 23011 ${ }^{\mathrm{T}}$, LMG 23012 ${ }^{\mathrm{T}}$, N. dentiae LMG $23015^{\mathrm{T}}$ and $N$. canis LMG $8383^{\mathrm{T}}$. High molecular mass DNA was prepared as described by Pitcher et al. (1989) and DNA-DNA hybridizations were performed with photobiotin-labelled probes in microplate wells as described by Ezaki et al. (1989) using an HTS7000 Bio Assay Reader (Perkin-Elmer) for fluorescence measurements. The hybridization temperature was $39^{\circ} \mathrm{C}$. Reciprocal experiments were performed for every pair of strains. The hybridization value between strains LMG $23011^{\mathrm{T}}$ and LMG $23012^{\mathrm{T}}$ was $42 \%$, which is in agreement with the previously reported value of $31 \%$ (Rossau et al., 1989). Hybridization values between these EF-4a and EF-4b reference strains and $N$. canis LMG $8383^{\mathrm{T}}$ (36 and $50 \%$, respectively) and $N$. dentiae LMG $23015^{\mathrm{T}}$ (31 and $43 \%$, respectively) were also low to intermediate. These DNADNA hybridization results demonstrate that EF-4a and EF$4 \mathrm{~b}$ isolates represent two distinct and novel species within this bacterial lineage.

All strains were biochemically characterized in a range of 66 conventional biochemical tests by methods described previously (Holmes et al., 1986). Certain strains were additionally tested for nitrite reduction through to gas by the method described by Holmes et al. (1975). The species descriptions as presented below are based on data obtained for the isolates presented in Table 1 and for an additional 19 strains of group EF-4a and 12 strains of group EF-4b studied by Holmes et al. (1990). Differential characteristics between isolates from group EF-4a and EF-4b and their closest phylogenetic neighbours are shown in Table 2.

Cellular fatty acid analysis was carried out with a loopful of well-grown cells after an incubation period of $48 \mathrm{~h}$. Fatty acid methyl esters were prepared, separated and identified using the Microbial Identification System (Microbial ID) as

Table 2. Phenotypic characteristics useful for differentiation of Neisseria animaloris sp. nov. and Neisseria zoodegmatis sp. nov. from related taxa

Taxa: 1, N. animaloris sp. nov (22 strains); 2, N. zoodegmatis sp. nov. (15 strains); 3, N. canis LMG $8383^{\mathrm{T}} ; 4, N$. dentiae LMG $23015^{\mathrm{T}}$; 5, U. suis (five strains; data from Vela et al., 2005). All data are from this study unless otherwise indicated. Results for nitrite reduction to gas were determined from only three strains of N. animaloris (LMG 23011 ${ }^{\mathrm{T}}$, LMG 23009 and LMG 23010) and three strains of $N$. zoodegmatis (LMG 23012 ${ }^{\mathrm{T}}$, LMG 23013 and LMG 23014). NA, Not available.

\begin{tabular}{|lccccc|}
\hline Characteristic & $\mathbf{1}$ & $\mathbf{2}$ & $\mathbf{3}$ & $\mathbf{4}$ & $\mathbf{5}$ \\
\hline Arginine dihydrolase activity & + & - & - & - & - \\
Facultatively anaerobic & + & + & - & + & + \\
Growth on MacConkey agar & + & + & + & + & - \\
Nitrite reduction & + & + & - & + & + \\
Nitrite reduction to gas & + & - & - & + & NA \\
\hline
\end{tabular}


described previously (Vandamme et al., 1992). N. canis, $N$. dentiae and strains from group EF-4a and EF-4b could all be distinguished through quantitative differences in their cellular fatty acid profiles (see Supplementary Table S1 in IJSEM Online). In particular, the relative distribution of $16: 1 \omega 7 c, 16: 0$ and 16:0 2-OH was useful to distinguish strains from group EF-4a and EF-4b.

The allocation of the two novel species to a specific genus is not straightforward given the polyphyletic nature of the genus Neisseria. Clearly, N. canis and N. dentiae are the nearest phylogenetic neighbours of both taxa. In a neighbour-joining phylogenetic tree, rather than clustering with the other Neisseria species, they form a distinct lineage together with $U$. suis. The sequence similarity levels of the $16 \mathrm{~S}$ rRNA genes of isolates from group EF- $4 \mathrm{a}$ and EF- $4 \mathrm{~b}, N$. canis and $N$. dentiae with $U$. suis range from $96 \cdot 8(\mathrm{EF}-4 \mathrm{a})$ to $95.5 \%$ (EF-4b). However, neither the EF-4a-U. suis lineage, nor the lineage composed of isolates from group EF-4a and EF-4b, N. canis, N. dentiae and U. suis, is supported by a high bootstrap value (Fig. 1). In general, these organisms are rather unreactive and there is little to distinguish members of the genera Neisseria and Uruburuella in the characters they exhibit. Although the capacity to grow in facultatively anaerobic conditions was reported to distinguish Uruburuella strains from members of the genus Neisseria (Vela et al., 2005) (which are generally considered strictly aerobic), we found the type strain of $N$. dentiae to be facultatively anaerobic, just like group EF-4a and EF4b strains. N. canis, however, is strictly aerobic. There are therefore no clear phenotypic grounds to distinguish the genus Uruburuella from the genus Neisseria (even if all of the members of the lineage composed of group EF-4a and EF-4b, N. canis, N. dentiae and U. suis were transferred into the genus Uruburuella). Therefore, pending a more general reassessment of the taxonomy of the genus Neisseria, we find it most appropriate to allocate strains from group EF-4a and EF-4b to the genus Neisseria.

\section{Description of Neisseria animaloris sp. nov.}

Neisseria animaloris (a.ni.mal.or' is. L. n. animal an animal; L. n. os the mouth; N.L. gen. n. animaloris of an animal's mouth).

Colonies are circular, convex, entire, opaque, shiny, smooth and haemolytic. All 22 strains studied by Holmes et al. (1990) are positive for acid production (in peptone water medium) from glucose, arginine dihydrolase production, catalase production, cytochrome oxidase production, growth at $37^{\circ} \mathrm{C}$, growth at room temperature $\left(18-22^{\circ} \mathrm{C}\right)$, growth on MacConkey agar and nitrate reduction. Most strains are positive for (exceptions in parentheses) fermentation in the Hugh and Leifson O-F test (negative: LMG 23009, CL 579/78; oxidative reaction: CL 608/78) and gelatinase production (plate method; CL 820/79). All strains are

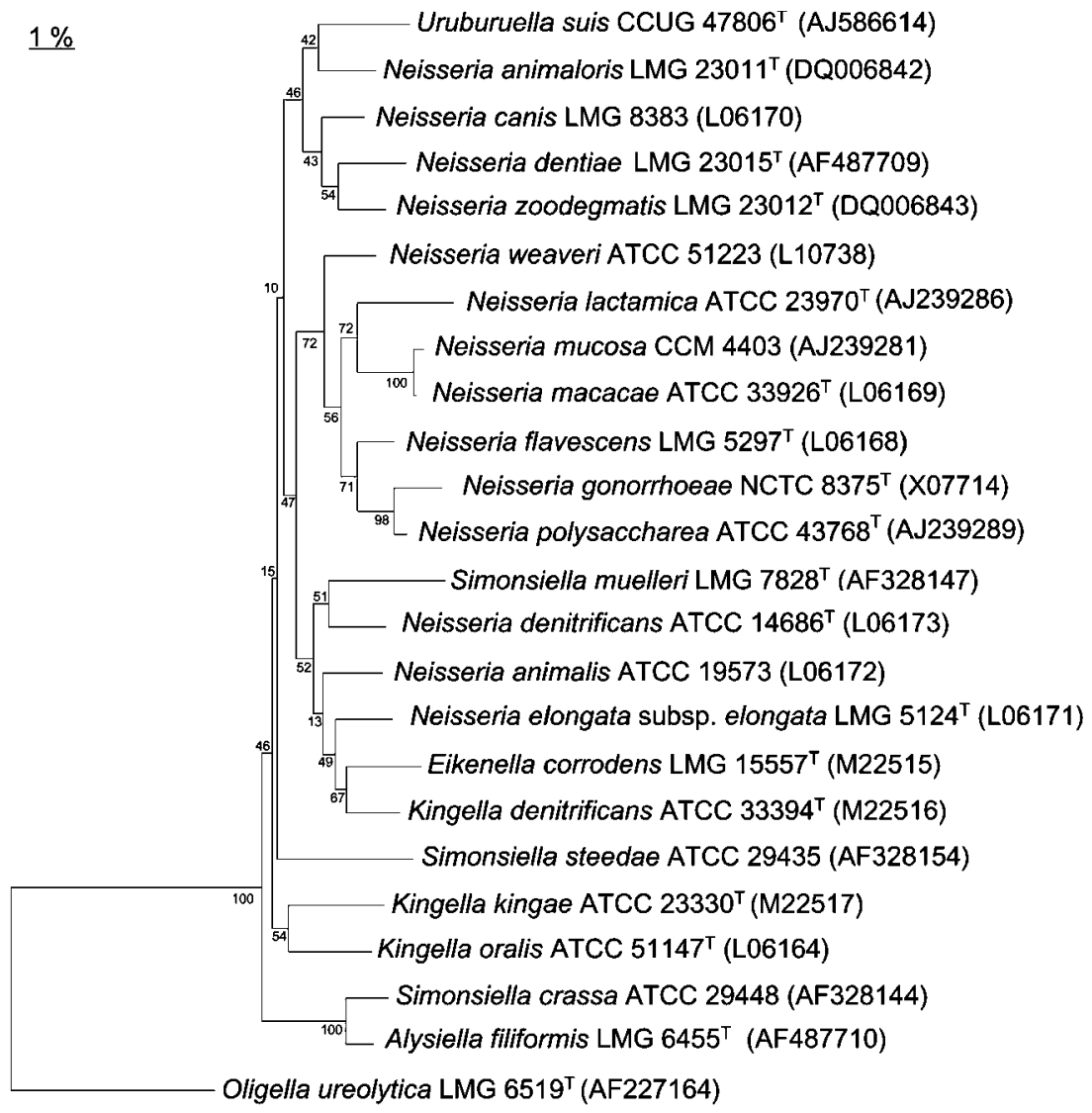

Fig. 1. Neighbour-joining phylogenetic tree based on 16S rRNA gene sequences showing the position of Neisseria animaloris sp. nov. (EF-4a) and Neisseria zoodegmatis sp. nov. (EF-4b). Bar, $1 \%$ sequence dissimilarity. 
negative for acid production (in peptone water medium) from adonitol, arabinose, cellobiose, dulcitol, glycerol, inositol, lactose, maltose, mannitol, raffinose, rhamnose, salicin, sorbitol, starch, sucrose, trehalose and xylose. All strains are negative for acetoin production (Voges-Proskauer test; incubation at $37^{\circ} \mathrm{C}$ for 2 days and incubation at room temperature for 5 days), casein digestion, gluconate oxidation, $\beta$-galactosidase production (ONPG test), gas production from glucose in peptone water medium, $\mathrm{H}_{2} \mathrm{~S}$ production (by lead acetate paper and triple-sugar iron agar methods), indole production, KCN tolerance, lysine decarboxylase production, malonate utilization, methyl red test at room temperature (incubation for 5 days), motility (hanging drop preparation at both $37^{\circ} \mathrm{C}$ and room temperature), ornithine decarboxylase production, phenylalanine deamination, pigment production, production of extracellular DNase, reduction of $0.4 \%(\mathrm{w} / \mathrm{v})$ selenite, urease production and utilization of citrate (Simmons' medium). Most strains are negative for gelatinase production (stab method; CIP 655.75, CIP 310.77, CIP 181.80), methyl red test at $37^{\circ} \mathrm{C}$ (incubation for 2 days; CL 820/79) and utilization of citrate (Christensen's medium; LMG $\left.23011^{\mathrm{T}}\right)$. DNA G $+\mathrm{C}$ content is around $50 \mathrm{~mol} \%$; the DNA $\mathrm{G}+\mathrm{C}$ content of the type strain is $49 \cdot 3 \mathrm{~mol} \%$ (Rossau et al., 1989). Characteristics for the type strain are the same as described above for the species except for the utilization of citrate in Christensen's medium, which is positive in the type strain.

The type strain, LMG $23011^{\mathrm{T}}\left(=\right.$ NCTC $12228^{\mathrm{T}}=$ CL 191/ $78^{\mathrm{T}}=$ ATCC $29858^{\mathrm{T}}=$ CDC D8251 $\left.1^{\mathrm{T}}\right)$, was isolated from a thumb wound in Wisconsin, USA. Strains LMG 23009 (=NCTC 12226) and LMG $23010(=$ NCTC 12227) are reference strains.

\section{Description of Neisseria zoodegmatis sp. nov.}

Neisseria zoodegmatis (zoo.deg' ma.tis. Gr. n. zoon an animal; Gr. n. degma a bite; N.L. gen. n. zoodegmatis of an animal's bite).

Colonies are circular, convex, entire, opaque, shiny, smooth and haemolytic. All 15 strains studied by Holmes et al. (1990) are positive for catalase production, cytochrome oxidase production, growth at $37^{\circ} \mathrm{C}$, growth at room temperature $\left(18-22^{\circ} \mathrm{C}\right)$ and growth on MacConkey agar. Most strains are positive for (exceptions in parentheses) acid production (in peptone water medium) from glucose (C5663, CL 149/79), fermentation in the Hugh and Leifson O-F test (negative: LMG 23014, A8412, B2939, D3138), gelatinase production (plate method; LMG 23012 ${ }^{\mathrm{T}}, \mathrm{B} 2939$, C5663, D7300, E764, E928, CL 149/79), nitrate reduction (B2939) and utilization of citrate (Christensen's medium; C3248, C5663, D3138, D7300, E928, CL 392/80). All strains are negative for acid production (in peptone water medium) from adonitol, arabinose, cellobiose, dulcitol, glycerol, inositol, lactose, maltose, mannitol, raffinose, rhamnose, salicin, sorbitol, starch, sucrose, trehalose and xylose. All strains are negative for acetoin production (Voges-Proskauer test; incubation at $37^{\circ} \mathrm{C}$ for 2 days and incubation at room temperature for 5 days), arginine dihydrolase production, casein digestion, gluconate oxidation, $\beta$-galactosidase production (ONPG test), gas production from glucose in peptone water medium, gelatinase production (stab method), $\mathrm{H}_{2} \mathrm{~S}$ production (by lead acetate paper and triple-sugar iron agar methods), indole production, $\mathrm{KCN}$ tolerance, lysine decarboxylase production, malonate utilization, methyl red test (both incubation at $37^{\circ} \mathrm{C}$ for 2 days and incubation at room temperature for 5 days), motility (hanging drop preparation at $37^{\circ} \mathrm{C}$ and room temperature), ornithine decarboxylase production, phenylalanine deamination, pigment production, production of extracellular DNase, reduction of $0 \cdot 4 \%(\mathrm{w} / \mathrm{v})$ selenite, urease production and utilization of citrate (Simmons' medium). The DNA $\mathrm{G}+\mathrm{C}$ content of N. zoodegmatis strains is around $50 \mathrm{~mol} \%$ (Rossau et al., 1989); the DNA G + C content of the type strain is $50 \cdot 5 \mathrm{~mol} \%$ (Rossau et al., 1989).

The type strain, LMG $23012^{\mathrm{T}}\left(=\right.$ NCTC $12230^{\mathrm{T}}=$ CL $194 /$ $78^{\mathrm{T}}=$ ATCC $29859^{\mathrm{T}}=$ CDC D5986 $6^{\mathrm{T}}$ ), was isolated from a dog-bite wound in Hawaii, USA. Strains LMG 23013 (=NCTC 12229) and LMG 23014 (=NCTC 12231) are reference strains.

\section{Acknowledgements}

T.C. and P.V. are indebted to the Fund for Scientific Research Flanders (Belgium) for a position as a postdoctoral fellow and research grants, respectively. We thank T. O. MacAdoo for advice on the etymology of names. We are extremely grateful to R. E. Weaver for the supply of cultures which made this study possible and B.H., in particular, would like to thank R. E. Weaver for years of fruitful collaboration. We thank P. Borman and E. Samyn for technical assistance.

\section{References}

Barrett, S. J. \& Sneath, P. H. (1994). A numerical phenotypic taxonomic study of the genus Neisseria. Microbiology 140, 2867-2891.

Bercovier, H., Escande, F., Chatelain, R. \& Weaver, R. E. (1982). Group EF-4 bacteria: a newly recognised pathogen. Adv Pathol 1, 27-30.

Coenye, T., Falsen, E., Vancanneyt, M., Hoste, B., Govan, J. R. W., Kersters, K. \& Vandamme, P. (1999). Classification of Alcaligenes faecalis-like isolates from the environment and human clinical samples as Ralstonia gilardii sp. nov. Int J Syst Bacteriol 49, 405-413.

Dees, S. B., Powell, J., Moss, C. W., Hollis, D. G. \& Weaver, R. E. (1981). Cellular fatty acid composition of organisms frequently associated with human infections from dog bites: Pasteurella multocida and groups of EF-4, IIj, M-5, and DF-2. J Clin Microbiol 14, 612-616.

Ezaki, T., Hashimoto, Y. \& Yabuuchi, E. (1989). Fluorometric deoxyribonucleic acid-deoxyribonucleic acid hybridization in microdilution wells as an alternative to membrane filter hybridization in which radioisotopes are used to determine genetic relatedness among bacterial strains. Int J Syst Bacteriol 39, 224-229.

Ganière, J. P., Escande, F., André-Fontaine, G., Larrat, M. \& Filloneau, C. (1995). Characterisation of group EF-4 bacteria from the oral cavity of dogs. Vet Microbiol 44, 1-9.

Holmes, B. \& Ahmed, M. S. (1981). Group EF-4: a Pasteurella-like organism. In Haemophilus, Pasteurella and Actinobacillus, pp. 161-174. 
Edited by M. Kilian, W. Frederiksen \& E. L. Biberstein. London: Academic Press.

Holmes, B., Lapage, S. P. \& Malnick, H. (1975). Strains of Pseudomonas putrefaciens from clinical material. J Clin Pathol 28, 149-155.

Holmes, B., Dawson, C. A. \& Pinning, C. A. (1986). A revised probability matrix for the identification of Gram-negative, aerobic, rod-shaped, fermentative bacteria. J Gen Microbiol 132, 3113-3135.

Holmes, B., Costas, M. \& Wood, C. A. (1990). Numerical analysis of electrophoretic patterns of group EF-4 bacteria, predominantly from dog-bite wounds of humans. J Appl Bacteriol 68, 81-91.

Pitcher, D. G., Saunders, N. A. \& Owen, R. J. (1989). Rapid extraction of bacterial genomic DNA with guanidium thiocyanate. Lett Appl Microbiol 8, 151-156.

Rossau, R., Vandenbussche, G., Thielemans, S., Segers, P., Grosch, H., Göthe, E., Mannheim, W. \& De Ley, J. (1989). Ribosomal ribonucleic acid cistron similarities and deoxyribonucleic acid homologies of Neisseria, Kingella, Eikenella, Simonsiella, Alysiella, and Centers for Disease Control Groups EF-4 and M-5 in the emended family Neisseriaceae. Int J Syst Bacteriol 39, 185-198.
Saitou, N. \& Nei, M. (1987). The neighbor-joining method: a new method for reconstructing phylogenetic trees. Mol Biol Evol 4, 406-425.

Tatum, H. W., Ewing, W. H. \& Weaver, R. E. (1974). Miscellaneous Gram-negative bacteria. In Manual of Clinical Microbiology, pp. 270294. Edited by E. H. Lenette, E. H. Spaulding \& J. P. Truant. Washington, DC: American Society for Microbiology.

Thompson, J. D., Gibson, T. J., Plewniak, F., Jeanmougin, F. \& Higgins, D. G. (1997). The CLUSTAL_X windows interface: flexible strategies for multiple sequence alignment aided by quality analysis tools. Nucleic Acids Res 25, 4876-4882.

Vandamme, P., Vancanneyt, M., Pot, B. \& 10 other authors (1992). Polyphasic taxonomic study of the emended genus Arcobacter with Arcobacter butzleri comb. nov. and Arcobacter skirrowii sp. nov., an aerotolerant bacterium isolated from veterinary specimens. Int J Syst Bacteriol 42, 344-356.

Vela, A. I., Collins, M. D., Lawson, P. A., García, N., Domínguez, L. \& Fernández-Garayzábal, J. F. (2005). Uruburuella suis gen. nov., sp. nov., isolated from clinical specimens of pigs. Int J Syst Evol Microbiol 55, 643-647. 